\title{
Buata B. Maleta, Les écrivains afro-antillais à Paris (1920-1960). Stratégies et postures identitaires
}

\section{Carminella Biondi}

\section{(2) OpenEdition}

1 Journals

\section{Edizione digitale}

URL: http://journals.openedition.org/studifrancesi/8091

DOI: 10.4000/studifrancesi.8091

ISSN: 2421-5856

\section{Editore}

Rosenberg \& Sellier

\section{Edizione cartacea}

Data di pubblicazione: 1 juillet 2009

Paginazione: 446

ISSN: 0039-2944

\section{Notizia bibliografica digitale}

Carminella Biondi, «Buata B. Maleta, Les écrivains afro-antillais à Paris (1920-1960). Stratégies et postures identitaires», Studi Francesi [Online], 158 (LIII | II) | 2009, online dal 30 novembre 2015, consultato il 13 janvier 2021. URL: http://journals.openedition.org/studifrancesi/8091 ; DOI: https://doi.org/10.4000/ studifrancesi.8091

Questo documento è stato generato automaticamente il 13 janvier 2021.

\section{(c)}

Studi Francesi è distribuita con Licenza Creative Commons Attribuzione - Non commerciale - Non opere derivate 4.0 Internazionale. 


\title{
Buata B. Maleta, Les écrivains afro- antillais à Paris (1920-1960). Stratégies et postures identitaires
}

\author{
Carminella Biondi
}

\section{NOTIZIA}

BUATA B. MALETA, Les écrivains afro-antillais à Paris (1920-1960). Stratégies et postures

identitaires, Paris, Karthala, 2008, pp. 465.

1 Lo scopo di questo corposo volume, che mi sembra rappresenti una pietra miliare nello studio di anni cruciali per la nascita del pensiero e della letteratura nera in area francofona, è esplicitato chiaramente in apertura di discorso: «Notre propos porte sur les stratégies d'émergences des écrivains originaires d'Afrique et des Antilles sous la domination française entre 1920 et 1960» (p.7). Un oggetto ed un tempo precisi, la cui importanza va però ben oltre i limiti indicati, perché costituiscono le solide radici di una albero che è diventato negli anni sempre più rigoglioso. Fin dall'inizio l'autore indica anche la metodologia scelta, sia pure rimodellata per adattarla alla materia trattata e per tener conto degli interventi di alcuni critici che vi si sono già confrontati: «la théorie des champs est la plus utile pour surmonter l'antinomie classique entre lecture interne et lecture externe» (p. 8). Il riadattamento della teoria di Bourdieu, operato in particolare per il tramite del filosofo Lambros Couloubaritsis, porta infine Maleta ad enunciare il percorso critico seguito: «Notre approche s'appuie donc sur trois axes: trajectoriel, historique et textuel: l'axe trajectoriel permet de déterminer les dispositions et les positions qu'occupent ces écrivains en examinant particulièrement leur stratégie de placement dans le champ littéraire et la situation de microcosme littéraire afro-antillais à Paris. L'axe his-torique montre la liaison avec le contexte français qui se modifie en fonction de certaines conditions (actualité, débats politiques, etc.). Enfin, l'axe textuel indique comment émerge dans les textes un modèle explicatif $\mathrm{du}$ rapport des écrivains au monde [...]. Dans cette optique, notre intention ne consiste 
pas à effectuer une analyse thématique, stylistique, imagologique, narratologique, linguistique, poétique, etc. Il s'agit plutôt de prélever dans le texte les différentes expériences familières [...] et de les lier aux enjeux trajectoriels et historiques» (p. 21). Le finalità della ricerca sono dunque chiaramente indicate nell'importante "Introduction générale", che si conclude con un'altrettanto chiara indicazione delle articolazioni del lavoro: la prima parte concerne l'affermarsi del miscocosmo afroantillano a Parigi negli anni Venti e Trenta del Novecento, mentre la seconda studia il consolidarsi di questa presenza. Risulta chiaro che per gli anni presi in considerazione, il punto di incontro delle varie periferie francofone è ancora unicamente e obbligatoriamente un centro rappresentato appunto dalla città di Parigi, che diventa così il champ littéraire all'interno del quale si costruisce l'identità degli autori studiati, in particolare (ma non solo): René Maran, Léon-Gontran Damas, Aimé Césaire, Léopold Sedar Senghor, Édouard Glissant, Mongo Beti.

2 Si tratta di un lavoro molto ricco, complesso e ben documentato che, al di là delle metodologie adottate più o meno condivisibili, apporta un contributo fondamentale alla conoscenza degli albori della "francofonia", sottolineando il ruolo svolto dal luogo di incontro, Parigi, ma anche da una mitologia africana più o meno consapevole nel processo di identificazione di questi scrittori provenienti dalle diverse colonie o excolonie francesi. Il volume poi, nei singoli capitoli che lo compongono, contribuisce ad approfondire la conoscenza degli autori sopra citati, tutti già molto noti, ma letti qui in una prospettiva del tutto inedita che ne arricchisce l'immagine e ci aiuta a meglio comprendere la genesi della loro opera. 